\title{
Um estudo da virtualização de processos: o uso de mundos virtuais com foco em ensino-aprendizagem
}

\author{
MÁRCIO NOVELI \\ Universidade Estadual de Maringá, Maringá, PR, Brasil
}

ALBERTO LUIZ ALBERTIN

Fundação Getúlio Vargas, São Paulo, SP, Brasil

RESUMO

Tecnologias de Informação e Comunicação (TICs) têm permitido que processos que dependiam da presença física de indivíduos ou objetos, em um mesmo lugar e tempo, ocorram sem esses limites. Dentre esses, o Processo Ensino-Aprendizagem (PEA) vem ganhando notoriedade, apesar de ainda persistirem dúvidas quando à adequação dessas tecnologias. Portanto, esta pesquisa teve o objetivo de identificar a relação entre requisitos de um processo e capacidades das TICs. Especificamente, foi estudada a adequação dos mundos virtuais à virtualização do PEA, com base na Teoria de Virtualização de Processo (TVP), por meio de evidências advindas de três cursos e analisadas por meio de técnicas de análise de conteúdo e escalonamento multidimensional. Isso resultou em um quadro sistematizado que permite entender o alinhamento entre TIC e requisitos de processo para a sua virtualização, evidenciando quais TICs têm viabilizado o desenvolvimento do PEA.

PALAVRAS-CHAVE

virtualização de processos; processo ensino-aprendizagem; mundos virtuais. 


\title{
A STUDY OF PROCESS VIRTUALIZATION: THE USE OF VIRTUAL WORLDS FOCUSED ON TEACHING-LEARNING
}

\begin{abstract} ICTs have been enabling the TLP.

KEYWORDS

process virtualization; teaching-learning process; virtual worlds.
\end{abstract}

Information and Communication Technologies (ICT) have allowed processes that used to depend on physical presence of individuals or objects at the same place and time to occur without such limitations. Teaching-learning process (TLP), for instance, has gained notoriety, although there is still doubt as to the suitability of these technologies. Thus, this research aimed to identify the relationship between requirements of a process and capabilities of ICTs. Adequacy of virtual worlds in TLP virtualization, starting from a general model based on the Process Virtualization Theory, was specifically assessed using evidence from three courses, with techniques of content analysis and multidimensional scaling. Results allow a better comprehension of the alignment between ICT and requirements of a process in its virtualization, also providing evidence that

\section{UN ESTUDIO DE LA VIRTUALIZACIÓN DE PROCESOS: EL USO DE MUNDOS VIRTUALES CENTRADOS EN ENSEÑANZA-APRENDIZAJE}

\section{RESUMEN}

Tecnologías de la Información y la Comunicación (TIC) han permitido que procesos que dependen de la presencia física de los participantes, individuos u objetos, en el mismo lugar y tiempo, ocurran sin estos límites. Entre estos, el proceso de enseñanza-aprendizaje (PEA) ha ganado notoriedad, a pesar de las dudas que persisten cuanto a su adecuación. Por ende, esta investigación buscó identificar la relación entre los requisitos del proceso y las capacidades de las TIC. Específicamente, con un estudio acerca de la adecuación de los mundos virtuales a la virtualización del PEA, basado en la Teoría de la virtualización de procesos, a través del estudio desde fuentes de evidencia de 3 cursos, analizadas utilizando análisis de contenido y escalamiento multidimensional. Esto resultó en un marco sistemático para entender la alineación entre los requisitos del proceso y las TIC para su virtualización, lo que ha permitido demonstrar que las TIC han permitido el desarrollo del PEA.

\section{PALAVRAS CLAVE}

virtualización de procesos; proceso enseñanza-aprendizaje; mundos virtuales. 


\section{INTRODUÇÃO}

Fazemos parte de uma sociedade em que cada vez mais as Tecnologias de Informação e Comunicação (TICs) têm permitido que processos antes dependentes da presença física de pessoas ou objetos em um mesmo local e momento ocorram agora sem esses limites, ao que se denomina virtualização de processos (Boughzala; Assar; Romano Junior, 2010; Overby, 2008).

Esse fenômeno, delimitado ao contexto do Processo Ensino-Aprendizagem (PEA) com a utilização de mundos virtuais, tem despertado o interesse em pesquisas em educação (Wang; Burton, 2013), e sua utilização se encontra em fase inicial (Keskitalo; Pyykkö; Ruokamo, 2011), havendo evidências controversas quanto à sua adoção (Dalgarno et al., 2011).

Portanto, partindo-se da Teoria de Virtualização de Processo (TVP), a qual propõe que um processo é mais propício a se tornar virtual se seus requisitos puderem ser preenchidos pelas capacidades das TICs, buscou-se responder à seguinte questão: "Como estão relacionados capacidades tecnológicas e requisitos de processo, na virtualização do PEA, com o uso de mundos virtuais?"

Essa questão tornou-se o objetivo desta pesquisa, que é identificar a relação entre requisitos de processo e capacidades das TICs na virtualização de processos, e foi respondida por um estudo empírico em que figuraram três cursos, dos quais foram extraídos dados primários a partir de registros em blogs e entrevistas com participantes do processo, os quais foram analisados por meio de técnicas de análise de conteúdo e escalonamento multidimensional.

As análises permitiram identificar alguns resultados que apontam o preenchimento de requisitos do PEA pelas capacidades dos mundos virtuais, de maneira a tornar a experiência desse processo virtual próxima à experiência face a face. Além de apontar fatores outros que têm dificultado que essa experiência aconteça em sua plenitude.

\section{PROCESSO ENSINO-APRENDIZAGEM E MUNDOS VIRTUAIS}

PEA pode ser considerado uma situação social complexa contendo múltiplos atores, cada um interagindo com intenções e interpretações próprias (Järvelä e Häkkinen, 2002), que envolve pessoas com diferentes habilidades, necessidades e expectativas (Campanella et al., 2008). Resumidamente, pode ser considerado um complexo sistema de interações entre professores e alunos (Kubo e Botomé, 2001).

Com o tempo, o elemento tecnológico passou a fazer parte desse processo, tornando-o ainda mais complexo. Essa participação é sustentada por dados do Instituto Nacional de Estudos e Pesquisas Educacionais Anísio Teixeira (INEP), sobre a expansão da educação a distância no Brasil (Alonso, 2010).

Tal avanço da utilização das TICs no PEA tem levado a uma releitura do conceito; por exemplo, a partir da perspectiva construtivista social, para Espasa e Meneses (2010, p. 278), “a educação a distância é conduzida no âmbito de uma comunidade, cujo objetivo final é a co-construção do conhecimento através de interações assíncronas entre alunos e professores em relação ao conteúdo ou a aprendizagem de tarefas (Scardamalia e Bereiter, 1994)". 
E, na prática, a utilização dessas tecnologias pode ser vista como um viabilizador da redução da distância entre os participantes do processo, a favor do processo educativo, como afirma Amarilha Filho (2011). E, para isso, "do ponto de vista pedagógico, o desafio está nas escolhas de ambientes virtuais que privilegiem não apenas a exposição de conteúdos, mas também a interação e a colaboração coletivas no processo de ensino-aprendizagem" (Amarilha Filho, 2011, p. 51). Pois, "para o aluno, aprender é transformar as aprendizagens em conhecimento, o qual, por sua vez, deve ser socializado não apenas por meio de tarefas solicitadas, mas também com os pares" (Amarilha Filho, 2011, p. 57).

Essa participação das TICs no PEA é aqui denominada virtualização, pois o processo ocorre sem a interação física de pessoas ou de pessoas e objetos envolvidos nele (OVERBY,2008, 2012), com a utilização de TICs, dentre elas, os mundos virtuais.

Os mundos virtuais surgiram com base nos avanços das tecnologias de realidade virtual e de uma variedade de outras tecnologias, como: gráficos de alto desempenho; interação humano-computador; jogos comerciais e simulações militares; aumento da escalabilidade das TICs (Morgan, 2009); bem como com "os recentes avanços em gráficos 3D, largura de banda e conectividade de rede, que facilitam novas formas de interação" (Kohler, Matzler e Füller, 2009, p. 398). São ambientes virtuais que as pessoas experimentam ao longo do tempo, como um mundo de interação social; são espaços sociais online persistentes, característica que os diferencia das tecnologias de realidade virtual a partir das quais foram desenvolvidos (Morgan, 2009; Schroeder, 2008).

Existem diversas plataformas que viabilizam a criação de mundos virtuais, como Hipibi, Project Wonderland e Second Life. Barnes (2009) afirma que há cerca de 70 mundos virtuais existentes ou em desenvolvimento, sem contar jogos online. Neste estudo, devido à disponibilidade da plataforma, focou-se na plataforma Second Life (SL).

Criada pela empresa Liden Lab, o SL consiste em uma terra virtual dividida em regiões de tamanho fixo (ilhas), onde os usuários interagem através de representações digitais chamadas avatares, que participam no desenvolvimento do ambiente virtual, criando objetos como carros, muros, árvores e edifícios (Varvello et al., 2011). Tanto eles quanto "suas roupas podem ser personalizados a um grau surpreendente com animações que variam de um aceno de mão a posições sexuais, mas rostos não têm qualquer expressão e os corpos não podem sentir o toque de outro avatar" (Cheal, 2007, p. 206). Ainda, o SL

oferece uma combinação singular de simulação $3 \mathrm{D}$ com conceitos de redes sociais dentro de uma rede de acesso aberto comercial oferecida pela Linden Labs: enquanto o servidor subjacente e a tecnologia de simulação estão sob o controle da empresa, o acesso à rede é gratuito e o conteúdo dos dados é em grande parte fornecido pela comunidade de usuários. (Rapanotti e Hall, 2011, p. 28)

Em função de suas características, mundos virtuais como o SL têm permitido virtualizar o PEA, o qual delimita o contexto desta pesquisa, estudado a partir da TVP. 


\section{A TEORIA DE VIRTUALIZAÇÃO DE PROCESSOS}

Estudos sobre a virtualização de processos com a adoção dos mundos virtuais, como os de Fetscherin e Lattemann (2008), Ibrahim et al. (2011) e Shen e Eder (2009), têm se baseado em modelos que focam aspectos sociais ou psicológicos associados aos indivíduos, como o Technology Acceptance Model-TAM (Davis, 1989), e o Unified Theory of Acceptance and Use tf Technology - UTAUT (Venkatesh et al., 2003).

Entretanto, outra perspectiva teórica, que considera a relação entre as características ou requisitos de um processo e as funcionalidades ou capacidades de uma tecnologia, tem merecido atenção. Isso porque, enquanto alguns estudos apontam que a utilização dos mundos virtuais é adequada para a virtualização do PEA (Keskitalo, Pyykkö e Ruokamo, 2011), outros são contrários (Lee e Berge, 2011).

Tal perspectiva pode ser associada à Teoria de Riqueza da Mídia - TRM (Daft e Lengel,1986), ao modelo de Adequação Tarefa-Tecnologia - ATT (Goodhue e Thompson, 1995), e à TVP (Overby, 2008). Dentre essas teorias/modelos, optou-se, nesta pesquisa, pela TVP. Tal decisão se deu em função de essa ser mais abrangente do que a TRM e complementar à ATT. No que diz respeito à TRM, esta

procura explicar a escolha da mídia para os diferentes processos de comunicação. Como tal, refere-se à interação pessoa-pessoa. A teoria de virtualização de processo se aplica à comunicação, bem como a outros tipos de processos (por exemplo, processos de trocas comerciais, processos educacionais, etc.). Ela envolve a interação pessoa-pessoa e pessoa-objeto. (Overby, 2008, p. 286)

No que diz respeito à ATT, a sua ideia fundamental e a da TVP são semelhantes (Barth e Veit, 2011). De acordo com a ATT, algumas tarefas, dadas as suas características, requerem certos tipos de funcionalidades das tecnologias. Dessa for$\mathrm{ma}$, a adequação das tecnologias às tarefas tende a diminuir, à medida que as tarefas tendem a ser mais demandantes em termos de requisitos ou as tecnologias ofertam menos funcionalidades. Contudo, a ATT não especifica quais poderiam ser essas funcionalidades e quais são as características a que essas tecnologias devem atender.

Nesse ponto, pode-se relacionar a TVP e a ATT, pois os principais constructos da TVP - características do processo (como requisitos de sensibilidade, requisitos de relacionamento etc.), constructos moderadores e capacidades das TICs - fazem paralelo com as características da tarefa e da tecnologia da ATT; ademais a variável dependente medida é semelhante em ambas (Overby; Konsynski, 2008, 2010).Esse paralelo permite que a TVP complemente a ATT, propondo um conjunto de constructos que podem ser usados para considerar por que o ajuste entre tarefa e tecnologia pode ser bom ou ruim (Overby e Konsynski, 2008, 2010).A TVP:

baseia-se na premissa de que alguns processos são mais passíveis de serem conduzidos virtualmente do que outros. [...] Ela fornece um quadro teórico para prever $e x$ ante quais processos são suscetíveis a serem realizados virtualmente no futuro, bem como para explicar ex post por que tentativas de virtualizar processos tiveram sucesso ou fracassaram. (Overby e Konsynski, 2008, p. 9) 
Para isso, a TVP se sustenta na definição de que "virtual"é a falta de interação física entre pessoas e entre pessoas e objetos nos processos; processos em que há interação física seriam processos físicos, e aqueles em que falta tal interação seriam virtuais (Overby, 2008). A partir dessa definição, a TVP busca explicar "quais os fatores que afetam o quão apropriado um processo é de ser conduzido virtualmente" (Overby, 2012, p. 111).

Esses fatores surgem do pressuposto de que processos, no nível de interação entre pessoas e pessoas ou entre pessoas e objetos, podem ser mais ou menos passíveis de se tornarem virtuais em função de seus requisitos e de capacidades que as TICs possuem e que podem preenchê-los. Dentre os constructos referentes às capacidades das TICs são incluídas as capacidades de representação, alcance, monitoramento e automação.

A capacidade de automação ocorre quando "o ator que era o responsável pela tarefa no processo físico é substituído por um sistema de informação. Se a tarefa não é automatizada, o ator mantém a responsabilidade pela tarefa" (Overby, 2012,p. 113).

A capacidade de representação é a "capacidade das TICs de apresentar informações relevantes para um processo, incluindo simulações dos atores e objetos dentro do mundo físico, suas propriedades e características, e como interagimos com eles"(Overby, 2008, p. 283).Essa capacidade permite, por exemplo, "que muitos requisitos sensoriais, tais como som e visão (e, em menor grau, tato, paladar e olfato) sejam replicados em processos virtuais baseados em TIC (Steuer, 1992; Suh e Lee, 2005)" (Overby, 2012, p. 113).

A capacidade de alcance se refere à "capacidade das TICs de permitir a participação no processo através tanto do tempo quanto do espaço (Broadbent et al. 1999; Evans; Wurster 2000)" (Overby, 2012, p. 113). E a capacidade de monitorar é a capacidade que as TICs possuem "de autenticar os participantes do processo e monitorar atividades (Zuboff, 1998)" (Overby, 2012, p. 113). Além dessas capacidades, a TVP inclui um conjunto de construtos que diz respeito a requisitos de processos. O Quadro 1 traz a definição de cada um dos constructos propostos pela TVP.

Esses constructos se relacionam, com os requisitos tendo um efeito negativo, inversamente proporcional, tornando um processo menos propício a ser virtualizado. Assim, quanto mais alto for um requisito, menor a chance de tornar determinado processo virtual. Por outro lado, as capacidades das TICs desempenham um papel como moderadoras nas relações entre os requisitos de um processo e sua virtualizabilidade, viabilizando-a.

Para a virtualizabilidade do processo - a variável dependente no modelo - não é definido originalmente nenhum constructo. Entretanto, Overby (2008) sugere que sua mensuração pode se dar como adoção ou satisfação e, ainda, Overby, Slaughter e Konsynski (2010) consideram a adequação como um constructo que poderia aumentar a capacidade explicativa do modelo. Esses três constructos foram mantidos, neste estudo, como indicadores de virtualização, pois já foi constatada relação entre eles na virtualização do PEA (Lin, 2012).

Para tanto, considerou-se adequação como "o grau que uma tecnologia auxilia um indivíduo a realizar seu portfólio de tarefas" (Goodhue e Thompson, 
1995, p. 16). Satisfação é definida como a afeição ou os sentimentos do usuário sobre a participação no curso, na aula ou em relação à utilização do mundo virtual (Bhattacherjee, 2001). A adoção foi substituída pelo constructo continuidade de uso, definido como a intenção dos participantes de continuar usando os mundos virtuais para o PEA (Bhattacherjee, 2001); pois os cursos estudados na pesquisa eram ex post, dado que os participantes já haviam adotado a tecnologia em questão no momento do estudo.

Ademais, a TVP em si também foi objeto de estudo, pois possui lacunas a serem preenchidas, considerando que "pode haver fatores que influenciam a virtualizabilidade para processos em um domínio, mas não para aqueles em outro. Esses fatores específicos do domínio não são abrangidos pela teoria de virtualização de processo" (Overby, 2008, p. 288). Em função disso, sugeriu-se um novo fator a ser considerado no modelo: o requisito de coordenação.

De acordo com Van De Ven, Delbecq e Koenig Junior (1976, p. 322), coordenar é "integrar ou reunir diferentes partes de uma organização para realizar um conjunto de tarefas coletivas." Sem destacar a noção de coletivo, Malone e Crowston (1994, p. 90) propõem simplesmente que "coordenar é administrar dependências entre atividades".

Apesar de as atividades interdependentes a serem coordenadas poderem ser desenvolvidas coletivamente, o trabalho interdependente não é desenvolvido apenas coletivamente. É necessário, também, considerar a coordenação de atividades realizadas individualmente e, ao mesmo tempo, interdependentes, pois "a fronteira entre as atividades individuais e coletivas é dinâmica, no sentido de que as pessoas continuamente alternam entre diferentes ações relacionadas ao trabalho. Atividades coletivas são pontuadas pelas atividades dos indivíduos e vice-versa"(Fjuk, Smørdal e Nurminen, 1997, p. 2).

Quadro 1 - Definição operacional de constructos da Teoria de Virtualização de Processo [adaptado de Overby, 2008]

\begin{tabular}{|l|l|}
\hline Requisitos & \multicolumn{1}{c|}{ Definição } \\
\hline Sensoriais & $\begin{array}{l}\text { Necessidade de os participantes de um processo serem capazes de apreciar } \\
\text { uma experiência sensorial completa, tanto do processo em si quanto de outros } \\
\text { participantes e objetos envolvidos. Essa experiência sensorial envolve as sensações } \\
\text { de ver, ouvir, sentir, provar e tocar outros participantes ou objetos do processo, bem } \\
\text { como a sensação geral que os participantes têm quando engajados no processo. }\end{array}$ \\
\hline De relacionamento & $\begin{array}{l}\text { Necessidade dos participantes de um processo de interagir uns com os } \\
\text { outros em um contexto social ou profissional, que geralmente leva à } \\
\text { aquisição de conhecimento, confiança e desenvolvimento de amizades. }\end{array}$ \\
\hline De sincronismo & $\begin{array}{l}\text { Grau em que as atividades que compõem um processo precisam } \\
\text { ocorrer rapidamente, com o mínimo atraso entre elas. }\end{array}$ \\
\hline De identificação & $\begin{array}{l}\text { Grau em que os participantes do processo requerem } \\
\text { a identificação dos outros participantes. }\end{array}$ \\
\hline De controle & $\begin{array}{l}\text { Grau em que os participantes do processo requerem a habilidade de } \\
\text { exercer controle sobre o comportamento dos outros participantes. }\end{array}$ \\
\hline
\end{tabular}


Portanto, a coordenação pode ser exercida sobre atividades interdependentes desenvolvidas individualmente, ou seja, entre indivíduos que dependem das atividades uns dos outros para desenvolver as suas próprias, mas que não trabalham em grupo; ou coletivamente, na qual os indivíduos desenvolvem suas atividades em grupo para alcançar um objetivo comum. Isso se dá por diversos mecanismos, advindos da necessidade de coordenar, os quais podem reduzir a complexidade, auxiliando a explicar a relação de dependência entre atividades interdependentes individuais ou coletivas (Schmidt e Simone, 1996).

Considerando a existência desses mecanismos, e apropriando-se dos conceitos de coordenação apresentados, estrutura-se aqui um conceito próprio, segundo o qual: coordenar é integrar, através de diversos mecanismos, um conjunto de atividades interdependentes, realizadas individual e/ou coletivamente, para alcançar um objetivo. No que diz respeito aos mecanismos, apesar de esta não ser uma lista exaustiva, citam-se os apresentados no Quadro 2.

Com base em Kraut et al.(2005), pode-se afirmar que o uso dos mecanismos de coordenação apropriados leva a uma melhor coordenação, contribuindo para o bom desempenho. Nesse ponto é possível identificar que as TICs, por meio de suas capacidades, são ferramentas úteis, pois a literatura aponta que os mecanismos de coordenação têm sido viabilizados por elas.

Dessa forma, há evidências da utilização das TICs como mecanismo para a coordenação por feedback, com vantagens e desvantagens próprias (Galegher e Kraut, 1990; Kraut et al., 1990), ou como mecanismos formais de coordenação (Malone e Crownston, 1994; Kraut et al., 1999).

\section{Quadro 2-Mecanismos de coordenação [elaboração própria]}

\begin{tabular}{|l|l|}
\hline Mecanismo & \multicolumn{1}{c|}{ Definição } \\
\hline $\begin{array}{l}\text { Mecanismos } \\
\text { formais }\end{array}$ & $\begin{array}{l}\text { Planos de ação codificados e impessoalmente especificados, como planos } \\
\text { preestabelecidos, agendas, previsões, regras, políticas e procedimentos } \\
\text { formalizados, e sistemas de informação e comunicação padronizados que, } \\
\text { uma vez implementados, requerem uso mínimo de comunicação verbal entre } \\
\text { tarefas e seus desenvolvedores (Van De Ven, Delbecq e Koenig Junior, 1976). }\end{array}$ \\
\hline $\begin{array}{l}\text { Mecanismos } \\
\text { informais }\end{array}$ & $\begin{array}{l}\text { Coordenação por comunicação, ou feedback, e por ajustamento mútuo; } \\
\text { ou seja, os indivíduos trocam informações sobre seu estado corrente } \\
\text { e ajustam seu comportamento em relação às ações e aos objetivos de } \\
\text { outros indivíduos (Thompson, 1967 apud Kraut et al., 2005). }\end{array}$ \\
\hline $\begin{array}{l}\text { Modelo mental } \\
\text { compartilhado }\end{array}$ & $\begin{array}{l}\text { Crença comum mantida entre os membros de um grupo sobre como } \\
\text { cada um irá se comportar, ou seja, procedimentos padrão e cursos } \\
\text { de ação pré-formados que permitem coordenação aos membros } \\
\text { do grupo sem comunicação explícita (Kraut et al., 2005). }\end{array}$ \\
\hline $\begin{array}{l}\text { Memória } \\
\text { transitiva }\end{array}$ & $\begin{array}{l}\text { "[... refere-se a uma divisão especializada do trabalho cognitivo } \\
\text { que se desenvolve dentro de uma equipe com relação à codificação, } \\
\text { armazenamento e recuperação do conhecimento de diferentes } \\
\text { domínios (Wegner, 1987)"(Choi, Lee e Yoo, 2010, p. 856). }\end{array}$ \\
\hline $\begin{array}{l}\text { Interação entre } \\
\text { indivíduos } \\
\text { e objetos }\end{array}$ & $\begin{array}{l}\text { Relação entre indivíduos e objetos, ou entre indivíduos indiretamente, } \\
\text { por meio de objetos, explicada pelos estudos sobre Computer Supported } \\
\text { Collaborative Work (CSCW), conforme Fjuk, Smordal e Nurminen (1997). }\end{array}$ \\
\hline
\end{tabular}


No que diz respeito à cognição compartilhada e à memória transitiva, Yoo (2001) identificou seu surgimento ao longo do tempo em times virtuais de estudantes de MBA, separados pelas dimensões tempo e espaço. Especificamente, Robey, Boudreau e Rose (2000) afirmam que a cognição compartilhada pode ser encorajada por meio de sistemas que conectem membros em aprendizagem organizacional, e Choi, Lee e Yoo (2010) demonstraram que as TICs facilitam o desenvolvimento da memória transitiva, a qual tem papel importante no PEA (Jackson e Moreland, 2009).

Por fim, em um conjunto de atividades que exige coordenação, uma série de artefatos/objetos pode ser introduzida para controlar o estado das coisas e gerir as relações entre atores, dependências e tarefas (Schmidt e Simone, 1996). Nesse sentido,

a literatura sobre trabalho cooperativo apoiado por computador e informática médica sugere que os artefatos cognitivos e sociais são ferramentas eficazes de apoio à coordenação em ambientes dinâmicos e que a tecnologia para automatizar ou digitalizar esses artefatos deve ser considerada como um complemento de coordenação informal, pessoal. (Ren, Kiesler e Fussel, 2008, p. 109)

Portanto, pressupõe-se que as TICs têm auxiliado a atender à necessidade de coordenação a partir de suas capacidades, permitindo reproduzir ou criar mecanismos de coordenação que possibilitem aos processos a tornarem-se virtuais, nesse sentido, podendo ser considerado um requisito para a virtualização de processos.

\section{METODOLOGIA}

Adotou-se uma abordagem qualitativa exploratória, permitindo identificar elementos contextuais do domínio específico - o PEA - e os efeitos da tecnologia específica - os mundos virtuais - a partir do modelo teórico da TVP para explicar a virtualização de processos; e quantitativa descritiva, permitindo avaliar e relacionar esses elementos.

O número de três cursos foi definido pela indisponibilidade de casos e pela dificuldade de acesso a respondentes. Assim, são reconhecidas uma hipotética ampla população e uma pequena subpopulação de casos acessíveis; isso ocorre em diversos estudos nos quais o tamanho da amostra tende a ser muito pequeno para uma seleção aleatória. Em função disso, foi retirada uma amostra intencional, com base na variedade e reconhecendo oportunidades para o estudo intensivo, considerando, como critério primário, não a possibilidade de generalização, mas a oportunidade para aprender, a partir desses casos, sobre o fenômeno em estudo (Stake, 2005).

A estratégia de análise dos dados foi a análise de conteúdo sobre um conjunto de evidências: entrevista com o professor responsável pelo curso 1 e mensagens postadas no blog do curso 1 , apenas as mensagens postadas no blog do curso 2 , e entrevistas e e-mails de alunos no curso 3.

Os blogs utilizados para comunicação entre os participantes ao longo dos cursos foram considerados fontes de evidências sobre sua percepção do processo, pois "são uma forma popular de autorrelato e autorreflexão" (Kaun, 2010, p. 134). Além disso, o fato de serem arquivados permite o "exame de processos sociais 
ao longo do tempo, [...] para lançar luz sobre os processos sociais no espaço e no tempo [...] também permitem o acesso às populações geograficamente ou socialmente retiradas do pesquisador (Hessler et al, 2003; Mann e Stewart, 2000)" (Hookway, 2008, p. 93).

Ainda, foram realizadas entrevistas focais com participantes do curso 3, conduzidas de forma espontânea e assumindo o caráter de uma conversa informal, mas seguindo um conjunto de perguntas preestabelecidas (Yin, 2001). Deve-se destacar que, entre o envio do e-mail aos alunos para participação na pesquisa e a realização das entrevistas, alguns alunos responderam sobre o aceite e incluíram espontaneamente suas impressões pessoais sobre o curso, as quais também foram consideradas fontes de evidências.

$\mathrm{Na}$ análise de conteúdo, a análise temática identificou temas que se referiam a constructos apresentados na revisão da literatura ou descobriu novos temas (Ryan e Bernard, 2003). O tema corresponde a uma regra de recorte do sentido, e não de forma, sendo os textos recortados em elementos portadores de significações isoláveis (Bardin, 2011). De acordo com Ryan e Bernard (2003, p. 87), "você sabe que você encontrou um tema quando você pode responder à pergunta: $\mathrm{O}$ que esta expressão é um exemplo de?”

Esses temas, com base na técnica análise de direcionamento, que avalia o juízo de valor do locutor a respeito do que os temas tratam (Bardin, 2011), foram avaliados e categorizados "por caixas", partindo-se dos constructos propostos pela TVP e apresentados na revisão da literatura. Para outros temas, que não se "encaixavam", foram criadas categorias seguindo o critério semântico, no qual os temas que estavam associados, por exemplo, à infraestrutura de TIC, foram agrupados na categoria "infraestrutura de TIC".

Esses temas, avaliados e categorizados, foram relacionados por meio de análise de coocorrências, assumindo que "coocorrências em textos indicam associações na mente de alguém” (Krippendorff, 2012, p. 205). Assim, associaram-se capacidades dos mundos virtuais e preenchimento ou não preenchimento dos requisitos na virtualização do PEA, bem como a outros elementos identificados.

A identificação de coocorrência de categorias foi limitada a unidades de contexto, ou seja, a uma unidade de compreensão ótima para codificar a unidade de registro que permite compreender sua exata significação (Bardin, 2011). No caso dos blogs, optou-se por usar como unidade de contexto o parágrafo. Assim, temas identificados em um mesmo parágrafo foram associados como coocorrências. Para as entrevistas, utilizou-se cada questão como uma unidade de contexto.

A identificação, a avaliação e a categorização de temas resultaram na criação de tabelas de frequência de coocorrência que formaram uma matriz de proximidade, apresentando quantas vezes uma mesma categoria foi identificada com outra categoria em uma mesma unidade de contexto, como um parágrafo ou uma pergunta.

A partir dessa matriz gerou-se um mapa que mostra as posições relativas das categorias. O princípio de mapeamento é de que, quanto maior for a proximidade em termos de números de coocorrências entre duas categorias, mais próximo essas duas categorias estarão localizadas no mapa (Leydesdorff e Vaughan, 2006).E, considerando a natureza não métrica dos dados nominais dos blogs e das entrevistas, 
esse mapeamento foi realizado com os dois métodos não métricos fornecidos pelo software UCINET.

A escolha entre os mapas gerados pautou-se por dois critérios: observou-se o ajuste dos pontos pela medida de desajuste STRESS - com base nos valores propostos por Lattin, Carroll e Green (2011); e o julgamento da configuração final do mapa considerou o critério da interpretabilidade das coordenadas, ou seja, "se a solução com $t$ dimensões fornece uma interpretação satisfatória, mas a solução com $(t-1)$ dimensões não fornece nenhuma estrutura adicional, pode ser bom utilizar apenas a solução de $t$ dimensões" (Kruskal, 1964, p. 16).

Esses mapas permitiram indicar o quão similares ou diferentes são as estruturas de associação dessas categorias (Leydesdorff e Vaughan, 2006), representando se as categorias positivamente ou negativamente avaliadas estiveram associadas e identificando como as capacidades das TICs, os requisitos do processo e outros fatores estiveram relacionados, conforme será descrito a seguir.

A análise dos dados dos cursos, a partir do conjunto de técnicas apresentadas, envolve a análise cruzada de casos, buscando identificar padrões entre os cursos estudados (Eisenhardt, 1989).

\section{CARACTERIZAÇÃO DOS CURSOS}

A seguir são descritos os três cursos que foram objeto de análise desta pesquisa. Os dados do primeiro curso foram uma combinação de dados de dois cursos que, por serem ministrados na mesma plataforma (SL) e pelo mesmo professor, foram considerados como um só para facilitar a análise.

Assim, o curso 1 foi um curso gratuito, baseado em um livro sobre educação a distância. Os inscritos compravam o livro se quisessem receber um certificado de conclusão do curso da editora, mas poderiam participar do curso gratuitamente, caso não quisessem receber o certificado.

Esse curso tinha oito encontros que cobriam os capítulos do livro e ocorreu, inicialmente, em uma ilha no SL. Entretanto, os encontros eram feitos em várias ilhas diferentes, pois fazia parte do curso conhecer locais que estavam utilizando o SL para educação no mundo. Além do SL, foi utilizado um blog de apoio durante o curso em que eram disponibilizados conteúdos da aula e esclarecidas dúvidas dos alunos, além de outras formas de contato, como e-mail e chat.

Entre 2007 e 2008, o curso 1 teve três turmas, respectivamente com 80, 70 e 50 alunos inscritos, de acordo com informações do professor que ministrou as aulas. Contudo a quantidade de participantes efetivos, ou seja, que não descontinuaram o curso (e, consequentemente, o uso do SL), ficou ao redor de $50 \%$ dos inscritos em todas as turmas.

A segunda versão do curso 1 foi baseada em um livro do mesmo professor sobre jogos e educação e também teve oito encontros que cobriam os capítulos do livro. Ocorreu em uma ilha no SL. Além do SL, também foi utilizado o blog e uma segunda plataforma para interação com os alunos.

Ainda, essa segunda versão do curso teve apenas uma turma em 2010 e, de acordo com o professor, que não conseguiu precisar a quantidade, teve menos 
inscritos do que o primeiro curso, provavelmente porque era um curso pago; não foi possível também precisar a quantidade de participantes efetivos, ou seja, que não descontinuaram o curso e, consequentemente, o uso do SL.

O curso 2 foi um "metacurso", ou seja, um curso no SL para aprender a utilizar o próprio SL. Era gratuito, sendo oferecido por uma instituição. As aulas ocorreram na ilha dessa instituição. Teve nove turmas entre 2008 e 2009, e era organizado ao redor de oito encontros. Ao final desses encontros, era fornecido um certificado ao participante que tivesse cumprido no mínimo $75 \%$ da carga horária.

Além do SL, foi utilizado um blog de apoio durante o curso em que eram disponibilizados conteúdos da aula e esclarecidas dúvidas dos alunos. E, de acordo com dados do blog, as turmas eram formadas por aproximadamente 20 alunos, tendo a quantidade de participantes efetivos ao redor de $60 \%$, ou seja, cerca de $40 \%$ dos participantes descontinuaram o curso.

O curso 3 foi realizado por um dos autores deste estudo e consistiu em um curso no SL que versava sobre a utilização da calculadora HP12c em matemática financeira, para alunos de graduação em administração pública de uma universidade participante do sistema Universidade Aberta do Brasil (UAB), matriculados na disciplina de Matemática Financeira, da qual um dos autores foi professor. Inicialmente, 64 alunos se inscreveram no curso. Contudo, desse total, $45 \%$ não participaram, $18 \%$ participaram, mas abandonaram o curso, e $37 \%$ participaram efetivamente até o fim.

\section{ANÁLISES TEMÁTICA, DE DIRECIONAMENTO E CATEGORIAL}

Uma vez caracterizados os casos estudados, passa-se à apresentação dos resultados das análises temática, de direcionamento e categorial. Quanto aos dados utilizados para essas análises, no curso 1 e no curso 2 foi possível levantar, por meio da identificação do tipo de autoria das postagens/mensagens no blog dos cursos, que as mensagens analisadas refletiram a percepção de, pelos menos, 46 e 25 participantes de cada curso, respectivamente, incluindo os professores. Essas postagens/ mensagens foram classificadas por curso e autor, conforme apresentado na Tabela 1.

No curso 3, a coleta de dados se deu com 23 alunos que aceitaram ser entrevistados, e com outros 8 alunos que não foram entrevistados, mas mandaram suas impressões acerca de sua participação no curso por e-mail.

Os dados obtidos a partir dos blogs do curso 1 e do curso 2 e das entrevistas com os participantes no curso 3 foram organizados e, então, submetidos às técnicas de análise temática e de direcionamento.

Tabela 1 - Quantidade e tipo de postagens analisadas nos cursos 1 e 2 [elaboração própria]

\begin{tabular}{l|c|c|c|c|c}
\hline & Post & MP & MA & MO & Total \\
\hline Curso 1 & 58 & 11 & 40 & 22 & 131 \\
\hline Curso 2 & 45 & 133 & 119 & 81 & 378 \\
\hline
\end{tabular}

Post: postagem de professor; MP: mensagem de professor; MA: mensagem de aluno; MO: mensagem de outros. 
A análise temática levou à identificação de temas que foram categorizados dentro de oito constructos da TVP, do constructo requisito de coordenação, dos três indicadores de virtualização e de três outros fatores, todos avaliados positiva, neutra ou negativamente.

A mensagem de um aluno no blog de um dos cursos exemplifica essa categorização e avaliação: "O Second Life é sem sombra de dúvida um espaço que nos dá a impressão (capacidade de representação+) que mesmo a distância estamos muito próximos (requisito de relacionamento+) e vivendo em um mundo real (requisito sensorial+)."

Aqui, o aluno considerou que o SL é uma ferramenta que representa a realidade, o que foi considerado uma avaliação positiva da capacidade de representação dessa tecnologia, preenchendo o requisito de relacionamento, "tornando mais próximo quem está distante”, ou seja, uma avaliação positiva desse requisito e também do requisito sensorial, por permitir ao participante ter a impressão de estar "vivendo em um mundo real".

Assim, procedeu-se à análise qualitativa dos dados, com a qual identificaram-se, conforme apresentado na Tabela 2, apenas as capacidades de alcance e de representação avaliadas positivamente, consistentemente nos três cursos.

Isso aponta que a utilização de mundos virtuais preencheu requisitos do PEA. Ou seja, a necessidade de representação de objetos e/ou participantes do processo, bem como de requisitos sensoriais, nos diferentes cursos, foi atendida por essa tecnologia, permitindo uma interação próxima à que se teria caso o processo fosse face a face.

Como se pode observar na Tabela 3, os requisitos sensorial e de relacionamento foram avaliados positivamente com maior frequência do que negativamente nos três cursos, o que sugere que foram preenchidos consistentemente pelos mundos virtuais. $\mathrm{O}$ requisito de sincronismo foi avaliado negativamente, dado consistente entre os três cursos, devido ao sincronismo ser mencionado, pelos alunos dos cursos, como um impeditivo para participar do processo, pois os mesmos tinham atividades conflitantes com os horários do curso; lembrando que os encontros nos mundos virtuais, assim como no mundo "real", são síncronos. Por fim, também foram iden-

Tabela 2 - Categorização dos temas encontrados nos casos como capacidades das TICs [elaboração própria]

\begin{tabular}{l|c|c|c|c|c|c}
\hline \multirow{2}{*}{ Categoria } & \multirow{2}{*}{ Tema } & \multirow{2}{*}{ Sigla } & \multicolumn{4}{c}{ Número de ocorrências } \\
\cline { 4 - 7 } & & & Curso 1 & Curso 2 & Curso 3 & Total \\
\hline \multirow{2}{*}{$\begin{array}{l}\text { Capacidade } \\
\text { de alcance }\end{array}$} & capacidade de alcance & calc & 3 & 0 & 0 & \multirow{2}{*}{102} \\
\cline { 2 - 7 } & capacidade de alcance+ & calc+ & 9 & 1 & 89 & \\
\hline \multirow{2}{*}{$\begin{array}{l}\text { Capacidade de } \\
\text { representação }\end{array}$} & capacidade de representação & crep & 30 & 4 & 0 & \multirow{2}{*}{87} \\
\cline { 2 - 7 } & capacidade de representação- & crep- & 1 & 1 & 0 & \\
\cline { 2 - 7 } $\begin{array}{l}\text { Capacidade } \\
\text { de automação }\end{array}$ & capacidade de representação+ & crep+ & 8 & 8 & 35 & \multirow{2}{*}{8} \\
\hline
\end{tabular}


tificados temas associados aos requisitos de autenticação, controle e coordenação, mas não foi possível precisar se foram preenchidos.

Os indicadores de virtualização, satisfação, adequação e continuidade de uso, apresentados na Tabela 4, também foram identificados e avaliados com maior frequência positivamente, de forma consistente nos três cursos. Isso aponta que participantes do processo se sentiram satisfeitos com o PEA viabilizado por meio dos mundos virtuais, acharam esse meio adequado e continuariam a usar a tecnologia futuramente para esse processo.

Tabela 3 - Categorização dos temas encontrados nos casos como requisitos do processo [elaboração própria]

\begin{tabular}{|c|c|c|c|c|c|c|}
\hline \multirow{2}{*}{ Categoria } & \multirow{2}{*}{ Tema } & \multirow{2}{*}{ Sigla } & \multicolumn{4}{|c|}{ Número de ocorrências } \\
\hline & & & Curso 1 & Curso 2 & Curso 3 & Total \\
\hline \multirow{4}{*}{$\begin{array}{l}\text { Requisito de } \\
\text { autenticação }\end{array}$} & requisito de autenticação- & paut- & 0 & 0 & 18 & \multirow{4}{*}{43} \\
\hline & requisito de autenticação+ & paut+ & 1 & 0 & 3 & \\
\hline & autenticação não é requisito & raut- & 0 & 0 & 7 & \\
\hline & autenticação é requisito & raut+ & 0 & 0 & 14 & \\
\hline \multirow{5}{*}{$\begin{array}{l}\text { Requisito } \\
\text { de controle }\end{array}$} & requisito de controle & pcon & 1 & 10 & 0 & \multirow{5}{*}{55} \\
\hline & requisito de controle+ & pcon+ & 0 & 0 & 14 & \\
\hline & requisito de controle- & pcon- & 0 & 0 & 7 & \\
\hline & controle não é requisito & rcon- & 0 & 0 & 12 & \\
\hline & controle é requisito & rcon+ & 0 & 0 & 11 & \\
\hline \multirow{4}{*}{$\begin{array}{l}\text { Requisito de } \\
\text { coordenação }\end{array}$} & requisito de coordenação & pcoo & 7 & 18 & 0 & \multirow{4}{*}{73} \\
\hline & requisito de coordenação- & pcoo- & 3 & 0 & 3 & \\
\hline & requisito de coordenação & pcoo+ & 2 & 0 & 17 & \\
\hline & coordenação é requisito & $\mathrm{rcoo+}$ & 0 & 0 & 23 & \\
\hline \multirow{4}{*}{$\begin{array}{l}\text { Requisito de } \\
\text { relacionamento }\end{array}$} & requisito de relacionamento- & prel- & 1 & 1 & 1 & \multirow{4}{*}{58} \\
\hline & requisito de relacionamento+ & prel+ & 6 & 4 & 22 & \\
\hline & relacionamento não é requisito & rrel- & 0 & 0 & 4 & \\
\hline & relacionamento é requisito & rrel+ & 0 & 0 & 19 & \\
\hline \multirow{4}{*}{$\begin{array}{l}\text { Requisito } \\
\text { sensorial }\end{array}$} & requisito sensorial- & psen- & 3 & 1 & 0 & \multirow{4}{*}{56} \\
\hline & requisito sensorial+ & psen+ & 4 & 2 & 23 & \\
\hline & sensação não é requisito & rsen- & 0 & 0 & 8 & \\
\hline & sensação é requisito & rsen+ & 0 & 0 & 15 & \\
\hline \multirow{4}{*}{$\begin{array}{l}\text { Requisito de } \\
\text { sincronismo }\end{array}$} & requisito de sincronismo- & psin- & 10 & 2 & 5 & \multirow{4}{*}{52} \\
\hline & requisito de sincronismo+ & psin+ & 0 & 0 & 21 & \\
\hline & sincronismo não é requisito & rsin- & 10 & 0 & 2 & \\
\hline & sincronismo é requisito & $r \sin +$ & 0 & 0 & 19 & \\
\hline
\end{tabular}


A Tabela 4 também indica que outros temas, não apontados pelos modelos teóricos utilizados, apareceram consistentemente nos três cursos e diziam respeito ao uso do mundo virtual, à infraestrutura de TIC e ao elemento lúdico.

Os temas que diziam respeito ao uso do mundo virtual foram agrupados em uma categoria denominada facilidade de uso percebida (Davis, 1989, p. 320), definida como o "grau que uma pessoa acredita que o uso de um sistema específico seria livre de esforço." E se distribuíram entre o curso 1 e o curso 3, apesar de haver consistentemente referência a dificuldades de uso nos três cursos. No primeiro, talvez por ser um curso que ensina a utilizar a ferramenta, a dificuldade em seu uso ficou inicialmente mais evidente. O que se pode notar nos temas levantados é que, ao longo do tempo, os participantes avançam por uma curva de aprendizado e a ferramenta deixa de apresentar dificuldades aos usuários.

$\mathrm{O}$ tema infraestrutura de TIC foi categorizado seguindo Albertin e Albertin (2009, p. 112), como a "infraestrutura de TIC inclui hardware, software operacional, comunicações, equipamento e suporte requerido para permitir [...] aplicações”, e também foi avaliado negativamente de forma consistente entre os cursos. Isso se deu principalmente em razão de problemas na infraestrutura que sustentava o curso, tais como: problemas no computador dos usuários, problemas no provedor de internet, problemas no servidor do SL etc.

Por outro lado, o tema categorizado como elemento lúdico teve avaliação positiva consistente entre os cursos. Isso é coerente com os achados de outros estudos sobre sua utilização (Verhagen et al.,2012), e plausível, pois o mundo virtual se parece com um jogo, dado que evoluiu a partir da tecnologia de jogos. Contudo não se pôde identificar se esse elemento é um requisito ou uma capacidade.

Tabela 4-Categorização dos temas encontrados nos casos como indicadores de virtualização e outros fatores [elaboração própria]

\begin{tabular}{|c|c|c|c|c|c|c|}
\hline \multirow{2}{*}{ Categoria } & \multirow{2}{*}{ Tema } & \multirow{2}{*}{ Sigla } & \multicolumn{4}{|c|}{ Número de ocorrências } \\
\hline & & & Curso 1 & Curso 2 & Curso 3 & Total \\
\hline \multirow{2}{*}{ Adequação } & adequação- & ade- & 0 & 1 & 0 & \multirow{2}{*}{43} \\
\hline & adequação+ & ade+ & 12 & 7 & 23 & \\
\hline \multirow{2}{*}{ Satisfação } & satisfação- & sat- & 17 & 4 & 0 & \multirow{2}{*}{98} \\
\hline & satisfação+ & sat+ & 23 & 34 & 20 & \\
\hline \multirow{2}{*}{$\begin{array}{l}\text { Continuidade } \\
\text { de uso }\end{array}$} & continuidade de uso- & cou- & 0 & 0 & 0 & \multirow{2}{*}{28} \\
\hline & continuidade de uso+ & cout & 1 & 4 & 23 & \\
\hline \multirow{2}{*}{$\begin{array}{l}\text { Infraestrutura } \\
\text { de TIC }\end{array}$} & infraestrutura de TIC- & infr- & 22 & 8 & 4 & \multirow{2}{*}{53} \\
\hline & infraestrutura de TIC+ & infr+ & 0 & 0 & 21 & \\
\hline \multirow{2}{*}{$\begin{array}{l}\text { Facilidade } \\
\text { de uso }\end{array}$} & operar o mundo virtual- & uso- & 19 & 2 & 4 & \multirow{2}{*}{44} \\
\hline & operar o mundo virtual+ & uso+ & 2 & 0 & 18 & \\
\hline $\begin{array}{l}\text { Elemento } \\
\text { lúdico }\end{array}$ & elemento lúdico+ & elu+ & 1 & 1 & 2 & 4 \\
\hline
\end{tabular}




\section{ANÁLISES DE COOCORRÊNCIA E ESCALONAMENTO MULTIDIMENSIONAL}

Uma vez identificados, avaliados e categorizados os temas, buscou-se sua associação pela análise de coocorrência. Consideremos a mesma mensagem anterior de um aluno, presente no blog de um dos cursos: "O Second Life é sem sombra de dúvida um espaço que nos dá a impressão (capacidade de representação+) que mesmo a distância estamos muito próximos (requisito de relacionamento+) e vivendo em um mundo real (requisito sensorial+)."

A identificação de coocorrências se deu, como nesta mensagem, considerando o parágrafo como uma unidade de contexto em que temas ocorrem; neste exemplo, três deles coocorrem: capacidade de representação+, requisito de relacionamento+, requisito sensorial+. Essa coocorrência permite realizar uma inferência sobre a estrutura de associação do aluno, o que há no seu pensamento acerca dos fatores identificados no PEA (Osgood, 2009).

$\mathrm{Na}$ construção de tabelas de coocorrência, foram eliminadas categorias em que não foi cabível realizar a análise de direcionamento, indicadas sem sinal positivo ou negativo, gerando-se coocorrências apenas das categorias avaliadas. As matrizes resultantes (como a matriz do caso 1), apresentadas na Tabela 5, serviram de base

Tabela 5 - Coocorrências de categorias para o curso 1 [elaboração própria]

\begin{tabular}{|c|c|c|c|c|c|c|c|c|c|c|c|c|c|c|c|c|}
\hline & $\underset{\text { d }}{\stackrel{+}{O}}$ & $\frac{+}{\frac{U}{J}}$ & $\frac{+}{\frac{0}{d !}}$ & $\begin{array}{l} \pm \\
\stackrel{+}{\partial} \\
\text { 언 }\end{array}$ & $\begin{array}{l}\text { 응 } \\
\text { 언 }\end{array}$ & 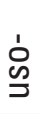 & $\stackrel{ \pm}{\frac{ \pm}{2}}$ & $\stackrel{+}{\overleftarrow{\sigma}}$ & 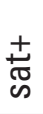 & $\begin{array}{l}+ \\
\text { 号 } \\
\text { J }\end{array}$ & $\stackrel{\stackrel{!}{!}}{\leftrightarrows}$ & 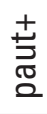 & $\frac{+}{\frac{d}{2}}$ & 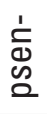 & 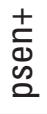 & $\stackrel{\stackrel{1}{c}}{\check{c}}$ \\
\hline ade + & 0 & 2 & 2 & 0 & 0 & 0 & 1 & 0 & 2 & 0 & 0 & 0 & 1 & 0 & 2 & 0 \\
\hline calc+ & 2 & 0 & 2 & 0 & 0 & 1 & 0 & 0 & 4 & 0 & 0 & 0 & 1 & 0 & 1 & 0 \\
\hline crep+ & 2 & 2 & 0 & 0 & 0 & 0 & 0 & 0 & 3 & 1 & 0 & 1 & 1 & 0 & 3 & 0 \\
\hline cou+ & 0 & 0 & 0 & 0 & 0 & 0 & 0 & 0 & 1 & 0 & 0 & 0 & 0 & 0 & 0 & 0 \\
\hline $\mathrm{rcoO}^{-}$ & 0 & 0 & 0 & 0 & 0 & 0 & 0 & 2 & 0 & 0 & 0 & 0 & 0 & 0 & 0 & 0 \\
\hline uso- & 0 & 1 & 0 & 0 & 0 & 0 & 0 & 7 & 1 & 0 & 5 & 0 & 0 & 3 & 0 & 0 \\
\hline elu+ & 1 & 0 & 0 & 0 & 0 & 0 & 0 & 0 & 0 & 0 & 0 & 0 & 0 & 0 & 0 & 0 \\
\hline sat- & 0 & 0 & 0 & 0 & 2 & 7 & 0 & 0 & 0 & 0 & 5 & 0 & 0 & 1 & 0 & 2 \\
\hline sat+ & 2 & 4 & 3 & 1 & 0 & 1 & 0 & 0 & 0 & 2 & 1 & 0 & 0 & 0 & 1 & 0 \\
\hline uso+ & 0 & 0 & 1 & 0 & 0 & 0 & 0 & 0 & 2 & 0 & 0 & 0 & 0 & 0 & 0 & 0 \\
\hline infr- & 0 & 0 & 0 & 0 & 0 & 5 & 0 & 5 & 1 & 0 & 0 & 0 & 0 & 1 & 0 & 0 \\
\hline paut+ & 0 & 0 & 1 & 0 & 0 & 0 & 0 & 0 & 0 & 0 & 0 & 0 & 1 & 0 & 0 & 0 \\
\hline prel+ & 1 & 1 & 1 & 0 & 0 & 0 & 0 & 0 & 0 & 0 & 0 & 1 & 0 & 0 & 0 & 0 \\
\hline psen- & 0 & 0 & 0 & 0 & 0 & 3 & 0 & 1 & 0 & 0 & 1 & 0 & 0 & 0 & 0 & 0 \\
\hline psen+ & 2 & 1 & 3 & 0 & 0 & 0 & 0 & 0 & 1 & 0 & 0 & 0 & 0 & 0 & 0 & 0 \\
\hline psin- & 0 & 0 & 0 & 0 & 0 & 0 & 0 & 2 & 0 & 0 & 0 & 0 & 0 & 0 & 0 & 0 \\
\hline
\end{tabular}


para a utilização da técnica de escalonamento multidimensional não métrico, por similaridade, realizado no software UCINET.

Dessa forma, o escalonamento multidimensional dos dados do curso 1 apresenta uma separação entre os constructos avaliados positivamente (em branco) e negativamente (em preto), conforme demonstra a Figura 1, com bom ajuste (STRESS de 0,028).

A leitura dessa figura indica que as categorias que expressavam requisitos preenchidos, como sensoriais (psen+), de relacionamento (prel+) e de autenticação (paut+), estiveram associadas àquelas que expressavam capacidades dos mundos virtuais, como capacidade de alcance (calc+) e de representação (crep+), e a indicadores positivos da virtualização do processo, como adequação (ade+), satisfação (sat+) e intenção de continuar o uso (cou+), bem como a outros fatores, como facilidade de uso (uso+) e elemento lúdico (elu+).

Ainda, observa-se na Figura 1 que as categorias que expressavam não preenchimento dos requisitos, como sensoriais (psen-), de coordenação (pcoo-) e de sincronismo (psin-), estiveram associadas à insatisfação (sat-) com o processo. Destaca-se que o não preenchimento não aparece associado à incapacidade do mundo virtual em representar ou permitir o alcance, e sim a outros fatores, como dificuldade de uso (uso-) e problemas de infraestrutura de TIC (infr-).

No curso 2, os constructos avaliados positiva (em branco) e negativamente (em preto) se agruparam em separado, permitindo demonstrar espacialmente sua associação na Figura 2, com excelente ajuste (STRESS de 0,002). Assim, as categorias que expressavam o preenchimento de requisitos, como sensoriais (psen+) e de relacionamento (prel+), apareceram associadas às capacidades do mundo virtual de representação (crep+) e de alcance (calc+) e a indicadores de virtualização, como

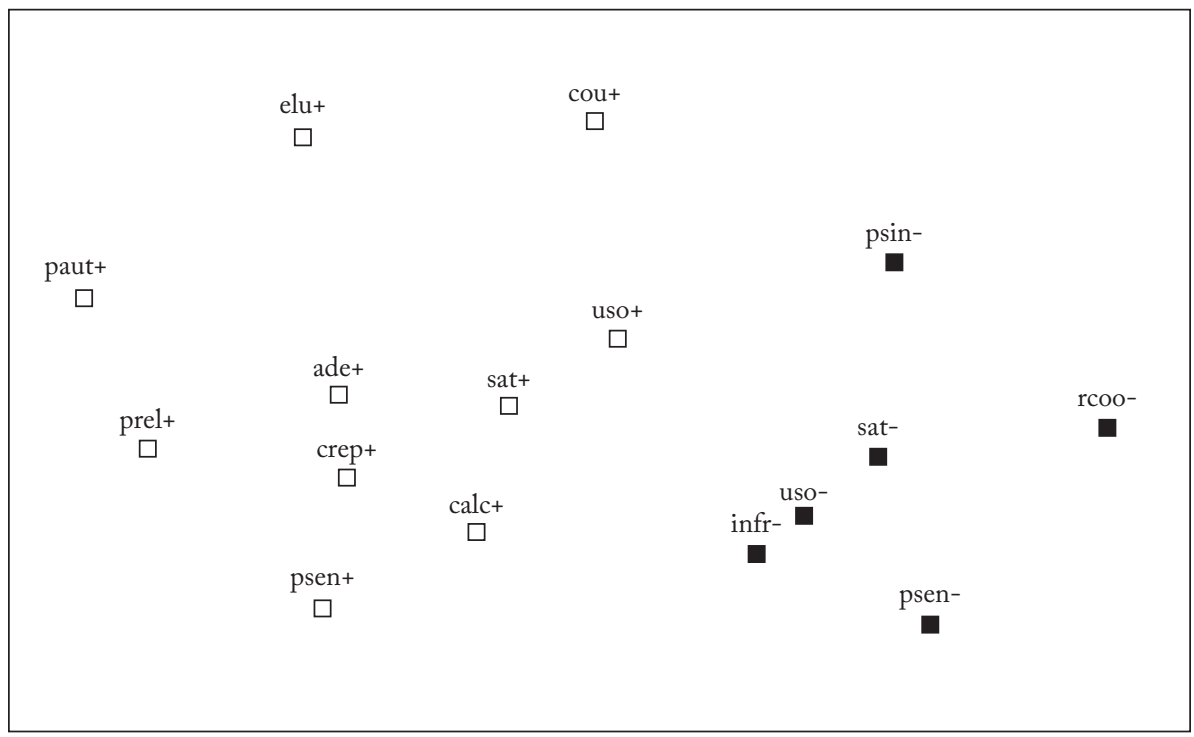

Figura 1 - Escalonamento multidimensional do curso 1 [elaboração própria] 
satisfação (sat+), adequação (ade+) e continuidade de uso (cou+), bem como a outro fator, o elemento lúdico (elu+).

A Figura 2 também apresenta quais das categorias que expressavam o não preenchimento de requisitos, especificamente o requisito sensorial (rsen-), estiveram associadas à insatisfação (sat-) com o processo conduzido pelo mundo virtual e à sua inadequação (ade-). Novamente, o não preenchimento não aparece associado à incapacidade do mundo virtual em representar ou permitir o alcance, e sim a problemas de infraestrutura de TIC (infr-) e à dificuldade de uso (uso-).

No curso 3, a unidade de contexto selecionada não permitiu incluir as categorias capacidade de alcance e de representação no mapeamento das coocorrências devido a distorções que essa unidade gerava. Contudo, com exceção de controle, os demais requisitos foram citados como preenchidos pela capacidade de alcance ou de representação nesse curso.

Separando-se as demais categorias em grupos, pode-se demonstrar espacialmente sua associação, conforme apresentado na Figura 3, com ajuste regular (STRESS de 0,117).

Contudo, no curso 3 não foi possível estabelecer as associações por polo, pois as respostas positivas dos alunos impediram o surgimento de um polo negativo ao redor do qual fatores negativos pudessem se agrupar. Dessa forma, conforme mostra

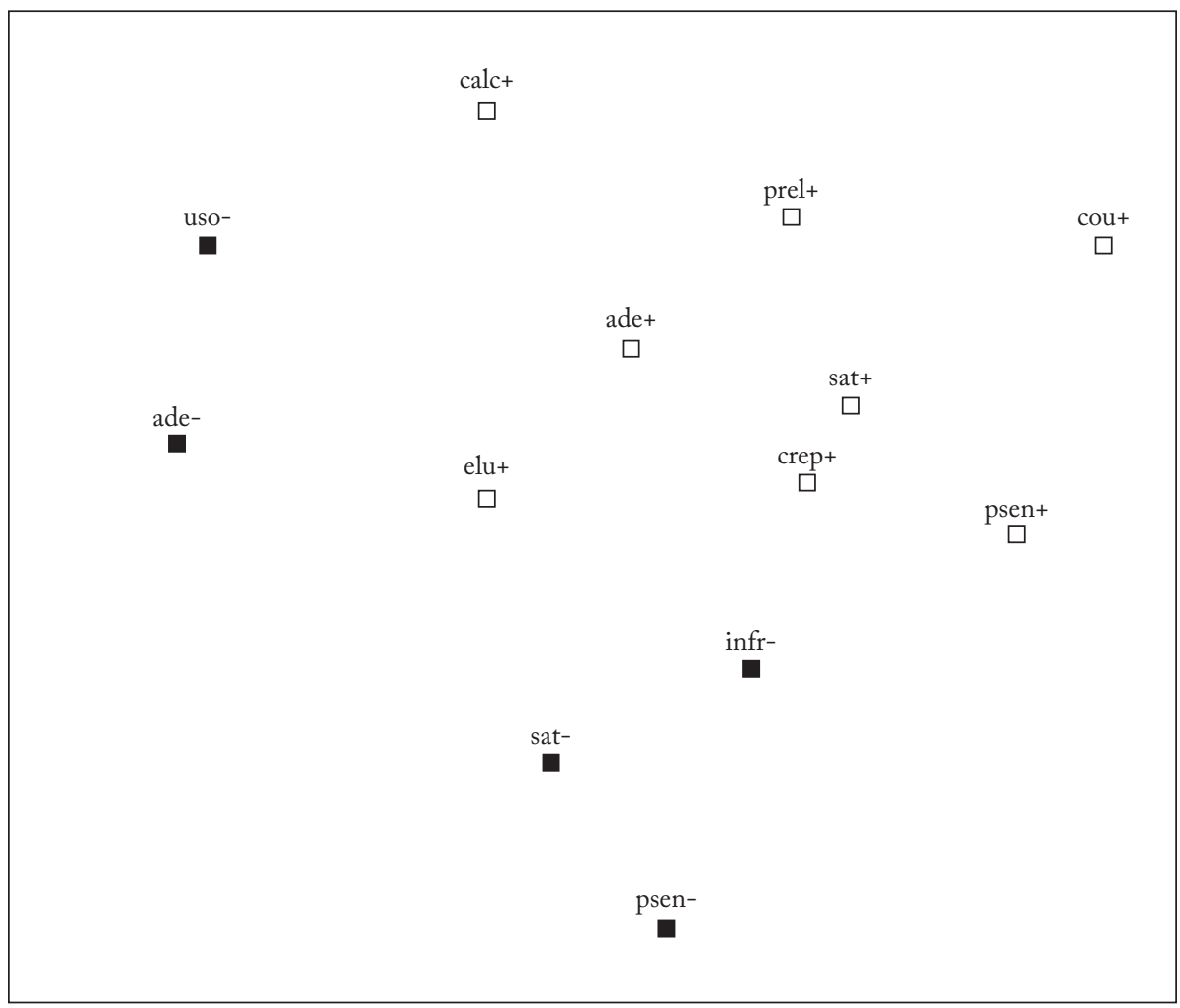

Figura 2 - Escalonamento multidimensional do curso 2 [elaboração própria] 
a Figura 3, dois círculos concêntricos foram desenhados para melhor representar visualmente o distanciamento dos fatores positivos (em branco) e negativos (em preto).

$\mathrm{Na}$ imagem superior direita da Figura 3, os indicadores de virtualização do processo - satisfação (sat+), adequação (ade+) e intenção de continuar o uso (cou+) - estiveram associados à facilidade de uso e à infraestrutura de TIC avaliadas positivamente, bem como às unidades de registro que expressavam que relacionamento (rrel+), sincronismo (rsin+) e coordenação (rcoo+), junto com os requisitos sensoriais e de autenticação, foram preenchidos pelas capacidades do mundo virtual.

Observa-se também, na Figura 3, que os fatores mais distantes do centro dos círculos são unidades de registro que expressam exatamente o contrário dos fatores presentes próximo ao centro do círculo. Essa relação entre os pares de fatores reforça o que foi afirmado sobre as associações do círculo menor. Deve-se destacar que o elemento lúdico, apesar de avaliado positivamente, apareceu com pouca associação com os demais fatores levantados, provavelmente devido à sua baixa ocorrência em relação aos mesmos.

\section{CONSIDERAÇÕES FINAIS}

A utilização de TICs para tornar processos virtuais tem avançado nas organizações e nos mais diversos processos. $\mathrm{E}$ isso tem sido uma realidade no cotidiano do PEA, o que gera a necessidade de entender as ferramentas disponíveis para a consecução desse novo paradigma tecnológico, considerando as necessidades do processo.

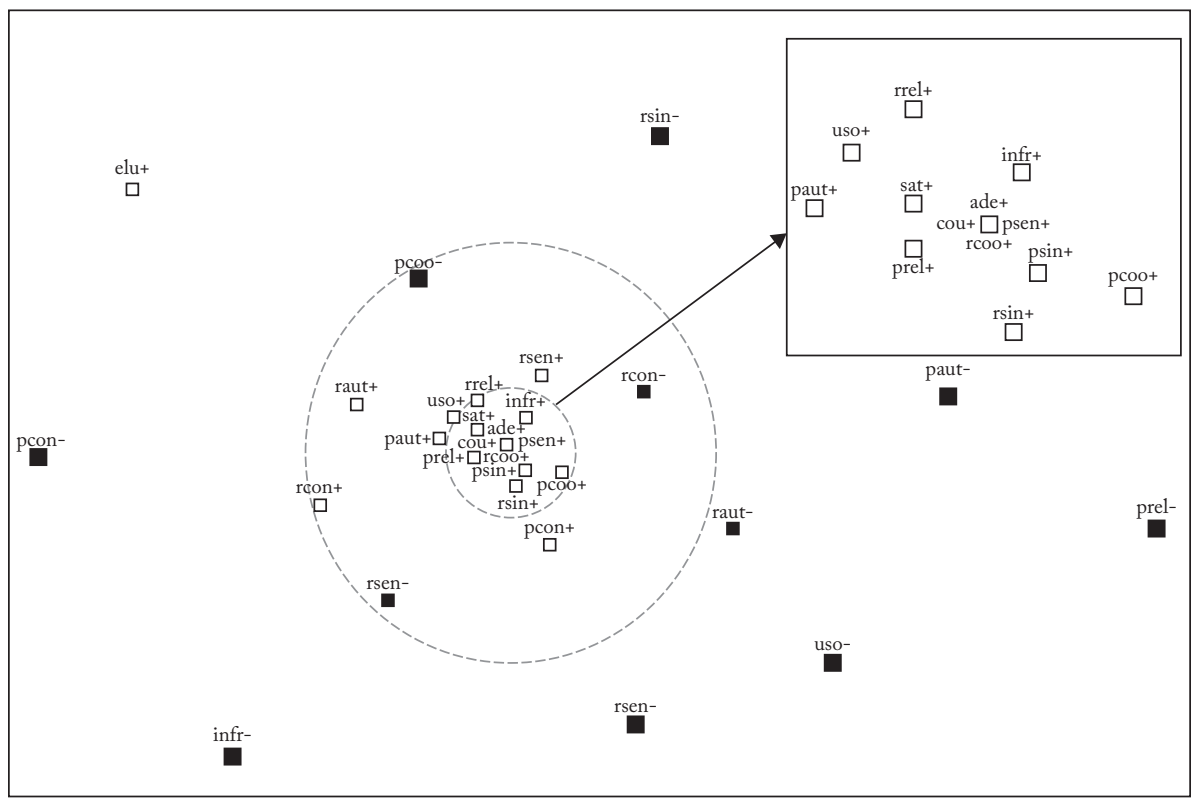

Figura 3 - Escalonamento multidimensional do curso 3 [elaboração própria] 
Ao longo dos três cursos analisados, constatou-se que os requisitos do PEA preenchidos estiveram associados às capacidades dos mundos virtuais e aos indicadores de virtualização, avaliados positivamente, dada a proximidade espacial que reflete sua relação.

Isso aponta para o fato de que a utilização de TICs, especificamente os mundos virtuais, permite uma rica interação dos participantes do PEA, mais próxima à interação face a face.

Dessa forma, as evidências levantadas permitiram interpretar que o preenchimento de requisitos, relacionado às capacidades dos mundos virtuais, promove a virtualização do processo.

Deve-se destacar que os requisitos identificados consistentemente entre os cursos estudados, mas que não puderam ser associados ou descritos quanto à sua avaliação, incluíram o requisito de coordenação proposto nesta pesquisa.

Observa-se também que, além dos fatores pressupostos no modelo geral da pesquisa, foi possível identificar a presença de um elemento lúdico, avaliado positivamente e associado a indicadores da virtualização do processo, e constatar fatores identificados, avaliados negativamente e associados consistentemente nos três cursos a indicadores da não virtualização do processo, como o sincronismo, a infraestrutura de TIC e a facilidade de uso.

Isso permitiu a constatação de que o não preenchimento de requisitos do PEA se deu não por problemas com as capacidades dos mundos virtuais, mas, conforme demonstrado pela proximidade espacial a indicadores de virtualização avaliados negativamente, por fatores como problemas com sincronismo, infraestrutura de TIC, e dificuldade de uso.

Tais resultados contribuem teoricamente com o espaço aberto pela TVP, descobrindo fatores e suas relações a partir da percepção dos participantes do processo, sendo que, empiricamente, esse mesmo conjunto de fatores e relações pode ser utilizado para orientar melhores práticas nas iniciativas de virtualização. Isso levaria um pesquisador a considerar não apenas as capacidades das TICs, mas também as limitações ou restrições das TICs na virtualização de um processo.

Além disso, na dimensão prática, a utilização desse modelo, levando em conta as considerações destacadas por este estudo, realizado no contexto nacional, permite refletir melhor sobre projetos de ensino a distância calcados no alinhamento entre capacidades de TIC e requisitos de processo, viabilizando uma decisão mais bem informada sobre a adoção e o uso de TICs.

Esse raciocínio se aplica a qualquer conjunto de iniciativas que busque utilizar TICs, não somente ao PEA, dado que aqui não é apresentado um rol determinista de constructos para esse único processo.

Deve-se levar em consideração uma limitação deste trabalho, que tratou de um conjunto de elementos qualitativos, categorizados em temas e quantificados para refletir possíveis associações de acordo com o objetivo geral traçado, apontando para um possível valor positivo das tecnologias inseridas no PEA, mas não utilizou técnicas de estatística inferencial para análise e extrapolação dos resultados a uma população para além dos cursos estudados. 


\section{REFERÊNCIAS}

Albertin, A. L.; Albertin, R.M. M. Tecnologia de informação e desempenho empresarial: as dimensões de seu uso e sua relação com os benefícios de negócio.2. ed. São Paulo:Atlas, 2009. Alonso, K. M. A expansão do ensino superior no Brasil e a EAD: dinâmicas e lugares. Educação É Sociedade, Campinas, v. 31, n. 113, p.1319-1335, out./dez. 2010. Disponível em: <www.scielo.br/pdf/es/v31n113/14.pdf>. Acesso em: 14 jun. 2012.

Amarilla Filho, P. Educação a distância: uma abordagem metodológica e didática a partir dos ambientes virtuais. Educação em Revista, Belo Horizonte, v. 27, n. 2, p.41-72, ago. 2011. Disponível em: <http://www.scielo.br/pdf/edur/v27n2/a04v27n2.pdf>. Acesso em: 4 jun. 2012. Bardin, L. Análise de Conteúdo. Lisboa: Edições 70, 2011.

Barnes, S. J. Modelling use continuance in virtual worlds: The case of second life. In: European Conference On Information Systems, 17, 2009, Verona, Italy. Proceedings... Verona, Italy, 2009. p. 1-12. Disponível em: <http://citeseerx.ist.psu.edu/ viewdoc/download;jsessionid=7C69D750DE19333C7ACB49577114EE92?doi=10.1. 1.229.1659\&rep=rep1\&type=pdf>. Acesso em: 17 out. 2012.

Barth, M.; Veit, D. Which processes do users not want online? - extending process virtualization theory. In: International Conference On Information Systems, 32, 2011, Shanghai, China. Proceedings... Atlanta, Ga: AISeL, 2011.p. 1-21. Disponível em: <http://aisel.aisnet.org/cgi/viewcontent. cgi?article=1287\&context=icis2011 >. Acesso em: 4 jun. 2012.

Bhattacherjee, A. Understanding information systems continuance: an expectationconfirmation model. MIS Quarterly, Minessota, v. 25, n. 3, p. 351-370, set. 2001. Disponível em: <http://www.jstor.org/discover/10.2307/3250921?sid=211052016337 11\&uid=3737664\&uid=2\&uid=4>. Acesso em: 23 mar. 2012.

Boughzala, I.; Assar, S.; Romano Junior, N. C. An e-government field study of process virtualization modeling. In: Group Decision \& Negotiation Conference, 10., 2010, Toronto, Canada. Proceedings... Delft - The Netherlands, 2010. p. 1-19. Disponível em: <http://www-public.int-evry.fr/ assar/pdf/Boughzala-Assar-Romano_ GDN2010.pdf $>$. Acesso em: 17 out. 2011.

Campanella, S. et al. E-learning platforms in the Italian Universities: the technological solutions at the University of Bari. Wseas Transactions on Advances in Engineering Education, Athens, v. 5, n. 1, p. 12-19, jan. 2008. Disponível em: <http://www.wseas. us/e-library/transactions/education/2008/25-283.pdf>. Acesso em: 7 jul. 2013.

Cheal, C. Second Life: hype or hyperlearning? On the Horizon, Emerald, v. 15, n. 4, p. 204-210, 2007. Disponível em: <http://www.emeraldinsight.com/doi/ pdfplus/10.1108/10748120710836228>. Acesso em: 20 fev. 2012.

Choi, S. Y.; Lee, H.; Yoo, Y. The impact of information technology and transactive memory systems on knowledge sharing, application, and team performance: a field study. MIS Quarterly, Minessota, v. 34, n. 4, p. 855-870, dez. 2010. Disponível em: <http:// misq.org/the-impact-of-information-technology-and-transactive-memory-systemson-knowledge-sharing-application-and-team-performance-a-field-study.html?SID= 05rjnu8ojm108atkns87cll6c7>. Acesso em: 7 abr. 2012. 
Daft, R. L.; Lengel, R. H. Organizational information requirements, media richness and structural design. Management Science, Baltimore, v. 32, n. 5, p. 554-571, maio 1986. Disponível em: <http:/www.communicationcache.com/uploads/1/0/8/8/10887248/ organizational_information_requirements_media_richness_and_structural_design. pdf>. Acesso em: 6 jun. 2010.

Dalgarno, B. et al. Institutional support for and barriers to the use of 3D immersive virtual worlds in higher education. In: Ascilite, 2011, Hobart, Australia. Proceedings... Australia: The University of Tasmania, 2011.p. 316-330. Disponível em: <http://www. ascilite.org/conferences/hobart11/downloads/papers/Dalgarno-full.pdf $>$. Acesso em: 15 nov. 2012.

Davis, F. D. Perceived usefulness, perceived ease of use, and user acceptance of information technology. MIS Quarterly, Minessota, v. 13, n. 3, p. 319-340, set. 1989. Disponível em: <http://www.jstor.org/discover/10.2307/249008?sid=2110524488994 1\&uid=2\&uid=4>. Acesso em: 27 abr. 2012.

Eisenhardt, K. . M. Building theories from case study research. The Academy of Management Review, v. 14, n. 4, p. 532-550, out. 1989. Disponível em: <http://www. jstor.org/stable/258557>. Acesso em: 13 mar. 2012.

Espasa, A.; Meneses, J. Analyzing feedback processes in an online teaching and learning environment: an exploratory study. Higher Education, Netherland, n. 59, p. 277-292, 2010. Disponível em: <http://link.springer.com/article/10.1007\%2 Fs10734-009-9247-4>. Acesso em: 13 mar. 2012.

Fetscherin, M.; Lattemann, C. User acceptance of virtual worlds. Journal of Electronic Commerce Research, California, v. 9, n. 3, p. 231-242, 2008. Disponível em: <http:// citeseerx.ist.psu.edu/viewdoc/download?doi=10.1.1.458.1177\&rep=rep1\&type=pdf $>$. Acesso em: 4 nov. 2010.

Fuuk, A.; Smørdal, O.; Nurminen, M. I. Taking articulation workseriously: an activity theoretical approach. Turku, Finland: Turku Centre for Computer Science (TUCS Technical Report, n. 120), 1997. Disponível em: <http://citeseerx.ist.psu.edu/viewdoc/ download?doi=10.1.1.18.3008\&rep=rep1\&type=pdf $>$. Acesso em: 12 nov. 2010.

Galegher, J.; Kraut, R. E. Computer-mediated communication for lntellectual teamwork: a field experiment in group writing. In: ACM Conference ON ComputerSupported Cooperative Work, 1990, Los Angeles, California. Proceedings... New York: ACM,1990.p.65-78. Disponível em: <http://www.cs.cmu.edu/ kraut/RKraut.site. files/articles/galegher90-CMCForIntellectualTeamwork.pdf >. Acesso em: 12 nov. 2010. Goodhue, D. L.; Thompson, R. L. Task-technology fit and individual performance. MIS Quarterly, Minessota, v.19, n.2, p. 213-236,jun.1995.Disponível em: <http://www.jstor.org/ discover/10.2307/249689?sid=21105244889941\&uid=2\&uid=4>. Acesso em: 20 out. 2009.

Ноокшау, N. "Entering the blogosphere”: some strategies for using blogs in social research. Qualitative Research, Los Angeles, London, New Delhi and Singapore, v. 8, n. 1, p. 91-113, 2008. Disponível em: <https://www.researchgate.net/profile/Nicholas_Hookway/publica tion/249731241_\%27Entering_the_blogosphere\%27_Some_strategies_for_using_blogs_ in_social_research/links/56e150bb08aec4b3333e543e/Entering-the-blogosphere-Somestrategies-for-using-blogs-in-social-research.pdf>. Acesso em: 7 dez. 2012. 
IвRAнim, R. et al. Student perceptions of educational games in higher education: an empirical study. Issues in Information Systems, v. 12, n. 1, p. 120-133, 2011. Disponível em: <http://iacis.org/iis/2011/120-133_AL2011_1635.pdf>. Acesso em:12 nov. 2010. Jackson, M.; Moreland, R. L. Transactive memory in the classroom. Small Group Research, Los Angeles, London, New Delhi and Singapore, v. 40, n. 5, p. 508-534, out. 2009. Disponível em: <http://sgr.sagepub.com/content/40/5/508.full.pdf $+h t m l>$. Acesso em: 24 maio 2012.

JÄrvelä, S.; Häkкinen, P. Web-based Cases in Teaching and Learning - the Quality of Discussions and a Stage of Perspective Taking in Asynchronous Communication. Interactive Learning Environments, London, n. 1, v. 10, p. 1-22, 2002. Disponível em: <http://www. tandfonline.com/doi/pdf/10.1076/ilee.10.1.1.3613\#.VNH-a53F-So>.Acesso em: 12 nov.2010. Kaun, A. Open-ended online diaries: capturing life as it is narrated. International Journal of Qualitative Methods, Edmond, v. 9, n. 2, p. 133-148, 2010. Disponível em: $<$ http://ejournals.library.ualberta.ca/index.php/IJQM/article/viewFile/7165/7022>. Acesso em: 16 abr. 2012.

Kesкitalo, T.; Ручккӧ, E.; Ruoкamo, H. Exploring the meaningful learning of students in second life. Journal of Educational Technology E Society, v. 14, n. 1, 2011. Disponível em: <http://www.ifets.info/journals/14_1/3.pdf>. Acesso em: 13 abr. 2012. Kohler, T.; Matzler, K.; Füller, J. Avatar-based innovation: using virtual worlds for real-world innovation. Technovation, Amsterdam, v. 29, n. 6-7, p. 395407, 2009. Disponível em: <http://www.sciencedirect.com/science/article/pii/ S0166497208001491>. Acesso em 05 mar. 2010.

Kraut, R. E. et al. Coordination and virtualization: the role of electronic networks and personal relationships. Organization Science, Baltimore, v. 10, n. 6, p. 722-740, nov./dez. 1999. Disponível em: <http://www.jstor.org/discover/10.2307/2640238?sid=2110526 4195071\&uid=4\&uid=2>. Acesso em: 10 out. 2011.

Kraut, R. E. et al. Coordination in teams: evidence from a simulated management game. [S.L.]: Human-Computer Interaction Institute, 2005. (Paper, N. 102). Disponível em: $<$ http://repository.cmu.edu/hcii/102>. Acesso em: 3 abr. 2012.

Kraut, R. E. et al. Informal communication in organizations: form, function, and technology. In: Oskamp, S.; Spacapan, S. (Eds.). Human reactions to technology: Claremont symposium on applied social psychology. Beverly Hills: Sage, 1990. p. 145-199. Disponível em: <http://www.cs.cmu.edu/ kraut/RKraut.site.files/articles/ kraut90-InformalCommInOrgs.pdf>. Acesso em: 12 nov. 2010.

Krippendorff, K. Content Analysis: an introduction to its methodology. 3. a ed. Thousand Oaks: Sage, 2012.

Krus Kal, J. B. Multidimensional scaling by optimizing goodness of fit to a nonmetric hypothesis, Psychometrika, Netherland, v. 9, n. 1, mar. 1964. Disponível em: <http://link. springer.com/article/10.1007\%2FBF02289565>. Acesso em: 1..$^{\circ}$ nov. 2012.

Киво, O. М.; ВотомÉ, S. P. Ensino-aprendizagem: uma interação entre dois processos comportamentais. Interação em Psicologia, Curitiba, v. 5, p. 133-152, 2001. Disponível em: $<$ http://revistas.ufpr.br/psicologia/article/view/3321/2665>. Acesso em: 20 jan. 2012. 
Lattin, J.; Carroll, D.; Green, P. E. Análise de dados multivariados. São Paulo: Cengage Learning, 2011.

Lee, A.; Berge; Z. L. Second life in healthcare education: virtual environment's potential to improve patient safety. Knowledge Management \& E-Learning: An International Journal, Hong Kong, v.3, n. 1, p. 17-23, 2011. Disponível em: <http:// www.kmel-journal.org/ojs/index.php/online-publication/article/view/95/75>. Acesso em: 6 set. 2011.

Leydesdorff, L.; Vaughan, L. Co-occurrence matrices and their applications in information science: extending ACA to the web environment. Journal of the American Society for Information Science and Technology, v. 57, n. 12, p. 1616-1628, out. 2006. Disponível em: <http://www.leydesdorff.net/aca/aca.pdf >. Acesso em: 10 set. 2012.

Lin, W.-S. Perceived fit and satisfaction on web learning performance: IS continuance intention and task-technology fit perspectives. International Journal of Human-Computer Studies, n. 7, p. 498-507, 2012.Disponível em: <http://www.sciencedirect.com/science/ article/pii/S1071581912000274>. Acesso em: 8 nov. 2012.

Malone, T. W.; Crowston, K. The interdisciplinary study of coordination. ACM Computing Surveys, New York, v. 26, n. 1, mar. 1994. Disponível em: <http://www. cs.unicam.it/merelli/Calcolo/malone.pdf >. Acesso em: 18 fev. 2011.

Morgan, G. Highly interactive scalable online worlds. Advances in Computers, San Diego, Amsterdam, v. 76, p. 75-120, 2009. Disponível em: <https://research.ncl.ac.uk/ game/research/publications/7168Cd01.pdf>. Acesso em: 18 fev. 2011.

Osgood, C. Contingency analysis: validating evidence and process. In: KrippendorfF, K.; Воск, M. A. (Eds.). The content analysis reader. Thousand Oaks: SAGE, 2009. cap. 3.1. p. 108-120.

Overby, E. Information migrating processes from physical to virtual environments: process virtualization theory. In: Dwivedi, Y. K.; Wade, M. R.; Schneberger, S. L. (Eds.). Information systems theory: explaining and predicting our digital society. [S.L.]: Springer, 2012. 1 v. cap. 6, p. 107-124. (Integrated Series in Information Systems, v. 28).

. Process Virtualization Theory and the Impact of Information Technology. Organization Science, Baltimore, v. 19, n. 2, p. 277-291, mar./abr. 2008. Disponível em: <http://pubsonline.informs.org/doi/pdf/10.1287/orsc.1070.0316>. Acesso em: 6 jul. 2011.

Overby, E.; Konsynski, B. Process virtualization: a theme and theory for the information systems discipline. In: Academy of Management Meeting, 2008, Anaheim, CA, EUA. Disponível em: <https://www.researchgate.net/publication/228319618_Process_ Virtualization_A_Theme_and_Theory_for_the_Information_Systems_Discipline >. Acesso em: 20 jan. 2012.

Overby, E.; Konsynski, B. Task-technology fit and process virtualization theory: an integrated model and empirical test. Atlanta: Emory Public Law, 2010. (Research Paper, n. 10-96). Disponível em: <http://ssrn.com/abstract=1567097 >. Acesso em: 12 jan. 2012. 
Overby, E.; Slaughter, S. A.; Konsynski, B. R. The design, use, and consequences of virtual processes. Information Systems Research, Baltimore, v. 21, n. 4, dez.p.700-710, 2010. Rapanotti, L.; Hall, J. G. Design concerns in the engineering of virtual worlds for learning. Behaviour E Information Technology, Oxon, v. 30, n. 1, p. 27-37, jan./ fev. 2011. Disponível em: <http://www.tandfonline.com/doi/abs/10.1080/014492 9X.2010.490922\#.VNiXNfnF-So>. Acesso em: 20 fev. 2012.

Ren, Y.; Kiesler, S.; Fussell, S. R. Multiple group coordination in complex and dynamic task environments: interruptions, coping mechanisms, and technology recommendations. Journal of Management Information Systems, London, v. 25, n. 1, p. 105130, 2008. Disponível em: <http://www.cs.cmu.edu/ kiesler/publications/2010pdfs/ RenKieslerFussell-JMIS-2008.pdf>. Acesso em: 19 mar. 2011.

Robey, D.; Boudreau, M.-C.; Rose, G. M. Information technology and organizational learning: a review and assessment of research. Accounting, Management $\mathcal{E}$ Information Technology, Amsterdam, n. 10, p. 125-155, 2000. Disponível em: <http://www. sciencedirect.com/science/article/pii/S095980229900017X>. Acesso em: 8 mar. 2011. Ryan, G. W.; Bernard, H. R. Techniques to identify themes. Field Methods, Los Angeles, London, New Delhi and Singapore, v. 15, n.1, p. 85-109, fev. 2003. Disponível em: <http://fmx.sagepub.com/content/15/1/85.abstract>. Acesso em: 27 ago. 2012.

Schmidt, K.; Simone, C. Coordination mechanisms: toward a conceptual foundation of CSCW system design. Computer Supported Cooperative Work: The Journal of Collaborative Computing, Netherlands, n.5,p.155-200,1996. Disponível em: <http://citeseerx.ist.psu.edu/ viewdoc/download?doi=10.1.1.11.4960\&rep=rep1\&type=pdf $>$. Acesso em: 16 fev. 2011.

Schroeder, R. Defining virtual worlds and virtual environments. Journal of Virtual Worlds Research, v. 1, n. 1, p. 1-3, 2008. Disponível em: <https://journals.tdl.org/jwwr/ index.php/jvwr/article/view/294>. Acesso em: 19 mar. 2011.

Shen, J.; Eder; L. B. Intentions to use virtual worlds for education. Journal of Information Systems Education, Mount Laurel, v. 20, n. 2, p. 225-233, 2009. Disponível em: <http://orange.utb.edu/msalas1/edtc6325/intentionstouseSL_education.pdf>. Acesso em: 7 mar. 2010.

Stake, R. E. Qualitative case studies. In: Denzin, N. K.; Lincoln, Y. S. (Eds.). The Sage handbook of qualitative research. 3. ${ }^{a}$ ed. Thousand Oaks: Sage, 2005. cap. 17. p. 443-466. Van De Ven, Andrew H.; Delbece, Andre L., Koenig Junior, Richard. Determinants of coordination modes within organizations. American Sociological Revierw, v. 41, n. 2, p. 322-338, abr. 1976. Disponível em: <http://www.jstor.org/discover/10.2307/20944 77? sid=21105819490633\&uid=2\&uid=4>. Acesso em: 16 fev. 2011.

Varvello, M. et al. Exploring second life. IEEE/ACM Transactions on Networking, v. 19, n. 1, 2011. Disponível em: <http://www.eurecom.fr/fr/publication/2919/copyright>. Acesso em: 5 maio 2011.

Venkatesh, V.et al. User acceptance of information technology: toward a unified view. MIS Quarterly, Minessota, v. 27, n. 3, p. 425-478, set. 2003. Disponível em: <http:// www.jstor.org $/$ discover $/ 10.2307 / 30036540$ ? $s i d=21105819726943 \& u i d=2 \& u i d=4>$. Acesso em: 5 nov. 2011. 
Verhagen, T. et al. Understanding users' motivations to engage in virtual worlds: a multipurpose model and empirical testing. Computers in Human Behavior, Amsterdam, n. 28, p. 484-495, 2012. Disponível em: <http://www.sciencedirect.com/science/article/ pii/S0747563211002378>. Acesso em: 19 mar. 2011.

Wang, F.; Burton, J. K. Second life in education: A review of publications from its launch to 2011. British Journal of Educational Technology, London, v. 44, n. 3, p. 357371, maio 2013. Disponível em: <http://onlinelibrary.wiley.com/doi/10.1111/j.14678535.2012.01334.x/pdf>. Acesso em: 20 jan 2012.

YIN, R. Estudo de caso: planejamento e métodos. 2. ${ }^{\mathrm{a}}$ ed. Porto Alegre: Bookman, 2001. Yoo, Y. Developments of transactive memory systems and collective mind in virtual teams. The International Journal of Organizational Analysis, Bingley, v. 9, n. 2, p. 187-208, 2001. Disponível em: <http://www.emeraldinsight.com/doi/abs/10.1108/eb028933>. Acesso em: 19 mar. 2011.

\section{SOBRE OS AUTORES}

MÁrcio Noveli é doutor em administração pela Fundação Getúlio Vargas (FGV-EASP). Professor da Universidade Estadual de Maringá (UEM). E-mail: marcionoveli@yahoo.com.br

Alberto Luiz Albertin é doutor em administração pela Universidade de São Paulo (USP). Professor da Fundação Getúlio Vargas (FGV-EAESP). E-mail: albertin@fgv.br 